\title{
UMA PARÁBOLA LITERÁRIA PARA APROXIMAR O UNIVERSO VIRTUAL DE SECOND LIFE. A INVENÇÃO DE MOREL: FANTÁSTICAS IMAGENS ${ }^{1}$
}

Céline Masson*

Tradução de Sergio Medeiros**

\section{RESUMO}

Este artigo toma como ponto de partida a parábola literária $A$ invenção de Morel, de Adolfo Bioy Casares, para analisar os temas de imagem e simulacro, tão presentes na contemporaneidade, tal como fica evidenciado em jogos como Second Life. Fazendo referências a áreas diversas como psicanálise, mitologia, filosofia, literatura e ópera, os autores tecem considerações a respeito da noção de corpo e da sua função em espaços virtuais.

Palavras-chave: psicanálise e literatura, imagem, corpo

\section{AbSTRACT}

A literary parabola to approximate Second Life's Virtual universe. The INVENTION OF MOREL: FANTASTIC IMAGES

This article makes use of the literary parabola The Invention of Morel, by Adolfo Bioy Casares, in order to analyze the subjects of image and simulacra, ever so present in contemporaneity, as we are able to observe in games such as Second Life. With references to diverse areas of knowledge such as psychoanalysis, mythology, philosophy, literature and opera, the authors discuss the concept of body and its function in virtual spaces.

Keywords: psychoanalysis and literature, image, body

* Clínica, Psicopatologia e Psicanálise na Escola Doutoral de Pesquisas em Psicanálise, Universidade Paris VII Denis Diderot.

** Doutor em Psicologia Clínica pela Pontifícia Universidade Católica do Rio de Janeiro (PUCRio); Professor da Universidade Santa Ursula. 
Antes de me debruçar na análise das imagens criadas na internet e especificamente em Second Life, parece-me interessante lembrar uma parábola literária. Trata-se do livro de Adolfo Bioy Casares (1973), A invenção de Morel. De fato, Second Life nos confronta com um novo universo e com novas experiências das quais os efeitos psíquicos são ainda de difícil apreensão.

A propósito de Pandora ${ }^{2}$, Jean-Pierre Vernant escrevia:

E, por conseqüência, seu lugar, sua função, apresenta o problema de saber o que são estas imagens, estas imitações. Qual é a relação entre uma deusa, sua estátua, e Pandora [...] o que é verdade, o que é falso? Como é possível ter uma aparência que salta aos olhos e que ao mesmo tempo seja contrária à realidade da coisa que se vê? (Vernant, 2006: 85-86).

Em suma, a questão fundamental apresentada por este mito e pela ficção que vamos estudar é aquela de saber o que é a verdade, o que é a ilusão e que espécie de loucura leva os homens a inventar máquinas para criar o engano, para jogar poeira sobre os olhos? O que vem, aliás, nos interrogar sobre as imagens atuais sem as quais não podemos mais passar e que se tornaram objetos de um verdadeiro culto. Há algumas décadas a religiāo das imagens ganhou nossa cultura, nossa sociedade, nossos meios de comunicação e nossa medicina. André Breton já prenunciava que os vivos seriam substituídos por suas imagens. Pode-se, desde então, falar de uma verdadeira iconomania? É o que nos convida pensar sobre este livro-mito de Casares (1973), A invenção de Morel, uma história que fala da separação daquele que está vivo, de sua imagem... as imagens vivem por elas próprias, às expensas dos corpos vivos que as originaram!

\section{A invenÇão de Morel de Adolfo Bioy Casares: A MÁQUINA INFERNAL}

Conhecemos a Olympia dos Contos de Hoffmann (Offenbach, 1881) boneca-autômato e mulher-simile, que é uma das invenções mais interessantes de simulacro na literatura. Mas há uma outra criação fantástica que é a máquina de Morel, descoberta pelo narrador da história ao desembarcar em uma ilha aparentemente deserta, fugindo da justiça de seu país. Ele chega em um barco a remo com uma bússola que ele não sabe usar e encontra neste lugar uma espécie de museu, uma capela e uma piscina. Ao explorar as construçóes vazias, ele descobre em seus subterrâneos algumas máquinas que serviriam provavelmente para fornecer água e eletricidade, graças a uma turbina acionada pelo mo- 
vimento das marés. Em uma sala fechada ele encontra outras máquinas que não compreende.

Quando se instala e começa a ter uma vida cotidiana, vê subitamente dois personagens como se tivessem aparecido espontaneamente em seu campo de visão ou em sua imaginação. Eles, no entanto, não o vêm. Os personagens saíram de um fonógrafo e passaram o tempo a conversar, a ouvir música e a dançar. Ele se deixa seduzir pelo charme de uma mulher que se chama Faustine e que vem, toda tarde, admirar o pôr do sol. Ele a observa, mas ela permanece indiferente em relação a ele e não percebe sua presença. Oculta-se para observá-la mais de perto, mas "o olhar dela passava através de mim, como se eu estivesse invisível" (Casares, 1973: 32), como se seus ouvidos e seus olhos não servissem pra ouvir e ver. Esta aparição fantasmática contribui para suscitar no narrador aquilo que Freud chama de um sentimento de inquietante estranheza (unheimliche), verdadeiro gerador de mal-estar. O narrador diz a propósito desta mulher: "sua tática não é humana. Eu sou a vítima...” (Casares, 1973: 41). Ela se apresenta com outro homem, um certo Morel, um inventor diabólico de uma máquina que projeta imagens da qual falaremos mais tarde. Esses personagens não vêem nem lhe dirigem nenhuma atenção. Movimentam-se como se a realidade material não lhes oferecesse nenhuma resistência, dançando no meio dos arbustos ou atravessando ninhos de víboras. Ele tenta compreender os segredos dessas apariçóes, pois suas presenças desaparecem da mesma forma que surgem. Os indivíduos invadem periodicamente a ilha sem que nenhum barco ou avião tenham sido ouvidos. Ele especula sobre algumas hipóteses. Talvez fosse vítima de alucinações decorrentes da subalimentação, talvez se tratasse de extraterrestres ou ainda de mortos vivos e talvez ele estivesse morto também: "é possível também que o ar das terras baixas, além de uma alimentação deficiente, tenha me tornado invisível” (Casares, 1973: 62). Entretanto, se dá conta de que não é invisível para os pássaros, para os ratos e para os mosquitos. Tenta compreender as aparições e desaparições dessas pessoas, é também uma busca enciumada sobre a natureza da relação entre Faustine e Morel. Ele diz ainda: "fico horrorizado diante da idéia de ser invisível; horrorizado pela idéia de que Faustine, tão próxima, possa se encontrar em um outro planeta [...]; mas eu estou morto, não posso ser tocado..." (Casares, 1973: 63). Podese ver a que ponto o fato de não ser visto, de não ser percebido através de um olhar (a consideração), pode proporcionar o sentimento de estar morto.

O mistério das aparições se esclarece pouco a pouco quando o narrador assiste a uma cena na qual Morel reúne seus amigos e lhes faz uma pequena conferência. Morel lhes anuncia que irá tomar suas imagens com um aparelho que inventou: 
meu abuso consiste em ter fotografado vocês sem autorização. Pois devo lhes dizer que não se trata de uma fotografia como as outras. Trata-se de minha última invenção, nós estaremos vivos nesta fotografia para sempre. Imaginem uma cena na qual estaria representada toda nossa vida durante esses sete dias. Somos nós que escolhemos. Todos os nossos atos foram gravados (Casares, 1973: 77-78).

Ele reproduz, assim, não somente suas imagens, mas os sons e os odores e a consistência dos seres e das coisas e pode assim repetir indefinidamente os trechos de vida gravados. Desta forma, lhe veio a idéia de gravar uma semana de sua vida com seus amigos, em um lugar paradisíaco, de maneira a que este pedaço de paraíso tenha uma existência eterna.

Qual é a função da radiotelefonia? Suprimir, no que diz respeito à audição, uma ausência especial: valendo-nos de transmissores e receptores, podemos nos reunir neste quarto para conversar com Madeleine, muito embora esteja há mais de vinte mil quilômetros no interior de Québec. A televisão consegue o mesmo, no que diz respeito à visão. [...].

Saí em busca de ondas e vibraçôes inalcançadas, de idealizar instrumentos para captá-las e transmiti-las. Obtive, com relativa facilidade, as sensações olfativas; as térmicas e as tácteis, propriamente ditas, exigiram toda a minha perseverança. [...]. Uma pessoa ou um animal ou uma coisa é, diante dos meus aparelhos, como a estação que emite o concerto que vocês estão ouvindo no rádio. Se abrirem o receptor de ondas olfativas, sentirão o perfume dos jasmins que estão junto aos seios de Madeleine, sem vê-la. Abrindo o setor de ondas tácteis, poderão acariciar sua cabeleira suave e invisível e aprender, como cegos, a conhecer as coisas com as mãos. Mas, se abrirem todo o conjunto de receptores, aparece Madeleine, completa, reproduzida, idêntica; não esqueçam que se trata de imagens extraídas dos espelhos, com os sons, a resistência ao tato, o sabor, os cheiros, a temperatura perfeitamente sincronizados. Nenhuma testemunha admitirá que são imagens. [...] Esta é a primeira parte da máquina; a segunda grava; a terceira projeta. Não precisa de telas ou papéis; suas projeções são bem acolhidas em todo o espaço. [...].

Tive uma surpresa: depois de muito trabalho ao congregar estes dados harmonicamente, encontrei pessoas reconstruídas, que desapareciam se eu desconectasse o aparelho projetor, viviam apenas os momentos passados em que se gravara a cena e, ao terminá-los, voltavam a repeti-los como se fossem parte de um disco ou de um filme que, uma vez terminado, torna-se a começar, mas que ninguém poderia distinguir das pessoas vivas. [...]. 
Congregados os sentidos, surge a alma. [...] Madeleine estava ali para a visão, Madeleine estava ali para a audição, Madeleine estava ali para o paladar, Madeleine estava ali pra o olfato, Madeleine estava ali para o tato: Madeleine estava ali (Casares, 1973: 80-84).

Vemos que a invenção de Morel vai bem além das diferentes técnicas de reprodução existentes como o cinema, a televisão, o vídeo, ou, mais recentemente, a holografia, que é um método de fotografar preservando o relevo dos objetos graças às interferências de raios laser. Sua técnica acrescenta o odor e a consistência táctil. Morel e seus amigos têm a consistência de seus corpos projetados no espaço e não somente suas silhuetas. A conseqüência dessa tomada de imagens é uma doença mortal e a morte que a ela se segue (os cadáveres dos convidados assim fotografados foram encontrados em um barco). Ele vai mesmo até falar de fantasmas monstruosos. A idéia de Morel é a perpetuidade, a vida eterna, na qual eles vão repetir todos os momentos da semana passada na ilha. $\mathrm{O}$ narrador experimenta o desgosto por estas simulaçôes de vivos e por suas atividades repetidas, mas estar apaixonado por uma dessas imagens era ainda pior para ele.

Os aparelhos de Morel remedeiam as ausências. O narrador se interroga: "não é impossível que toda a ausência somente seja espacial... de uma forma ou de outra, a imagem, o contato, a voz daqueles que não vivem mais devem residir em algum lugar..." (Casares, 1973: 92). O narrador pode, assim, dormir ao pé de Faustine sem que ela o perceba. Ele resolve viver perto dessas imagens.

De que se constitui a famosa máquina? O narrador nos explica após explorar o local que a abriga:

eu pude reconhecer, além da bomba d'água e da geradora de eletricidade, já mencionadas, os seguintes itens: a) um grupo de geradoras de corrente elétrica ligadas à turbina que se encontra nas terras baixas; b) um grupo fixo de receptores, gravadores e projetores, conectados a uma rede de aparelhos de maneira a cobrir toda a ilha; c) três aparelhos portáteis receptores, gravadores e projetores, para as exposições isoladas (Casares, 1973: 109).

Ele vai testar a máquina fazendo funcionar os receptores e os projetores: as flores, as moscas e as rãs que ele foca são reproduzidas e aparecem como reais. Cometeu a imprudência de colocar sua mão esquerda diante do receptor e, ligando o projetor, sua mão aparece como um objeto a mais. Uma vez tomadas as imagens, as flores, as moscas e as rãs morrem ao fim de algumas horas, "as cópias sobrevivem..." (Casares, 1973: 110). O narrador se lembra do horror que certos povos têm pela imagem dos seres vivos, um terror que repousa "na crença segundo 
a qual, quando se faz a imagem de uma pessoa, sua alma passa para a imagem e a pessoa morre" (Casares, 1973: 112). Morel e seus amigos estão mortos, mas o narrador pensa sobretudo em sua Faustine, de quem não resta mais do que uma miragem e, para esta, ele não existe. A vida é, então, sem interesse para ele, pois vive com uma imagem que ele não atingirá jamais.

Como disse Walter Benjamin (1997), a reprodutibilidade priva os seres de sua aura, esta aura que se refugia nos rostos. Vemos, no exemplo de Casares, que a reprodutibilidade dos seres vivos lhes tira esta aura, isto é, aquilo que lhes dá uma consistência, uma presença. Estes seres dependem de uma máquina e, se esta se desligar, eles desaparecem. Benjamin disse que a técnica da reprodução "separa aquilo que é reproduzido do domínio da tradição. Ao multiplicar as reproduções, ela substitui a presença única pela presença massiva. E quando ela autoriza a reprodução a ir ao encontro daquele que a recebe na situação onde este se encontra, atualiza aquilo que é reproduzido" (Benjamin, 1997: 24).

\section{O APAGAMENTO DOS CORPOS E A VIDA DAS IMAGENS}

Encontramo-nos diante de uma ilustração daquilo que Baudrillard (1994) chamará "a antecedência dos simulacros"; os simuladores atuais tentam fazer coincidir o real com seus modelos de simulação. A diferença entre real e simulacro tende a tornar-se ínfima, este é o projeto diabólico de alguns cientistas. O objeto de desejo do narrador é uma ilusão que convoca suas fantasias. Esta ilusão consiste na perseguição de uma mulher morta que é uma imagem viva repetindo a vida (a partir de uma semana de férias em uma ilha) e, para reunir-se à imagem (do amor), é preciso ser um corpo morto, isto é, uma imagem. O corpo, lugar da morte, da precariedade, obstáculo ao desejo, nós o reencontramos neste conto que parece metaforizar o virtual. Não há desejo que valha nem amor que dure sem a libertação do corpo (Le Breton, 1999). Tratar-se-ia, então, de se desembaraçar deste corpo que ocupa muito espaço e faz obstáculo aos desejos. Retirar o corpo é se dar os meios de reencontrar a imagem do outro do amor, imagem de um amor sem corpo onde a sexualidade é remanejada sem contestação. Este amor virtual (por imagens) tem como órgão sexual o olho e sua função, o olhar: aliás, não dizemos lavar o olho ${ }^{3}$ para olhar com prazer um bela mulher, um objeto de cobiça?

Estamos diante de um relato enigmático de tocante atualidade. Esse texto interroga a relação do homem com o mundo e suas representações (a morte, a vida, o amor), mundo de realidades obscuras e de criaçôes tecnológicas de máquinas que simulam o viver. "De Galactea ${ }^{4}$ à Eva do futuro, o apelo ao cyborg ressoa de longa data em nossas sociedades como um ideal a ser atingido" (Le Breton, 
1999: 201). As tentações do virtual nos seduzem freqüentemente contra nossa vontade (é o que acontece com os amigos de Morel), e neste sentido o autor enuncia antecipadamente o temor contemporâneo das ambiçôes sem limite da ciência. Em suma, não se deveria desconfiar daqueles que nos querem bem?

A extrema contemporaneidade, como diz Le Breton, encoraja o apagamento do corpo, sua metamorfose em dados manipuláveis virtualmente. $\mathrm{O}$ amor sem corpo ou o amor em imagens exacerba o olhar e o conjunto de sensaçôes que o acompanham (Le Breton dá o exemplo da cybersexualidade ou do corpo na internet). Esta humanidade aqui, diz ele ainda, se concebe mal quando está sem conexões com os processos técnicos. Após os consideráveis avanços da ciência, somos e seremos cada vez mais concebidos no cruzamento da máquina com o ser vivo. A mutação do homem em direção à máquina conjura o destino do organismo que inexoravelmente tende à doença e à morte. $\mathrm{O}$ estado máquina do homem o predestina à perpetuidade de uma existência na qual os limites serão incessantemente empurrados, alargados. A novela de Casares põe em cena um mundo no qual as interações sociais somente são possíveis na condição de se entrar no jogo das imagens. Vemos que, nesta perspectiva (que já se enuncia), não será mais possível se ver sem a imagem. Didier Sicard (2002) dizia, em seu livro La médicine sans le corps, que os estudantes de medicina de hoje ficariam horrorizados com a idéia de apalpar os corpos e preferem vê-los por trás das telas das máquinas, vê-los em sua "realidade aumentada", ver sua reconstituição ou reconstrução através da imagem. Em suma, um corpo virtual sem odor, sem voz para dele falar: "A obsolescência do corpo é certamente um absurdo, mesmo se ela é uma das palavras de ordem da extrema contemporaneidade, ela põe em andamento um possante imaginário que não é sem conseqüência sobre a percepção e sobre as imagens do homem ou da máquina” (Le Breton, 1999: 222).

Os artistas da extrema contemporaneidade pressentiram as modificações deste corpo (tanto no corpo social quanto no corpo biológico, sexuado e sensual), e suas obras testemunham as perspectivas que estão por vir: corpo protético, corpo máquina, corpo aberto, corpo imagem, corpo virtual... Paul Ardenne (2001) evoca este pressentimento dos artistas face à história:

o tratamento artístico do corpo próprio do século XX se revela em concordância com os acidentes simbólicos maiores registrados pela história: 1) abandono quase definitivo da concepção do corpus como essência divina; 2) crescimento do materialismo que abriu caminho para as teorias do homem-máquina, base de uma relação mais técnica do que ética em relação ao corpo; 3) crise profunda, e sem dúvida irreversível, do humanismo, que precipitou as tragédias da 
história, a começar pela solução final. [...] A representação artística do corpo copia esta evolução (Ardenne, 2001: 9).

Este "tratamento artístico do corpo" constitui uma certa "política do corpo" (e da saúde) que trata seu futuro esteticamente. Os corpos, despossuídos da morte e projetados em uma eternidade construída como um ideal, encontram-se apartados da história e do tempo. Os corpos-máquinas reutilizáveis segundo a vontade têm seu destino ou natureza tomados. É proibido morrer e, pior ainda, é proibido estar doente. A doença é o horror que é preciso eliminar; o corpo deve estar sem qualquer traço daquilo que lembra a morte. O corpo é, então, uma imagem, como aquela de Morel, uma invenção diabólica para fazer crer que ainda se está vivo: um engana-a-morte com sua potência escópica. É bem isso que se encontra no fundo da imagem? O que encontramos no fundo das imagens?, para retomar o título de um livro de Jean-Luc Nancy (2003).

\section{NO FUNDO DAS IMAGENS}

De que é feita a imagem? Titus Lucretius (99b.C.-55b.C./ 2000), em seu De rerum natura ${ }^{5}$, no parágrafo intitulado Natureza dos simulacros, se interroga sobre a composição da imagem em "elementos sutis". As coisas emitem os simulacros que se espalham de diversas formas no espaço, mas existem também, nos diz ele, outras imagens que nascem espontaneamente e se formam a partir delas mesmas no ar (como as nuvens). Ele volta a descrever a formação dos simulacros. Estes se separariam dos objetos a partir da emissão de átomos.

Quando estes elementos encontram os corpos porosos, eles atravessam o obstáculo, mas quando encontram a aspereza da pedra ou uma matéria ou a dureza da madeira, se rompem, sem poder enviar fielmente nenhum simulacro. Ao contrário, quando se interpõe um corpo brilhante e compacto, assim como um espelho, nenhum destes fenômenos se realiza. [...] O resultado é que desta superfície os simulacros refluem em direção a nós [...] da superfície dos corpos escorrem impalpáveis texturas de impalpáveis figuras (Lucretius, 99 b.C-55 b.C/2000: 269).

Para Lucretius, é nas imagens que reside o princípio da visão: sem elas nenhuma coisa pode ser vista.

A imagem mostra ${ }^{6}$. Por definição, ela é uma mostração ${ }^{7}$, como diz Jean-Luc Nancy (2003). A imagem é da ordem do monstro, signo que avisa sobre uma ameaça divina. Ela é freqüentemente excessiva, trans-gressiva, abrindo a vista pela 
força da presença, não tanto pela aparência e pelo aspecto, mas por sua realidade nua. A imagem é metamorfose das formas que excedem ou desaparecem, se deformam ou se redirigem. E tal afirmação de Nancy me parece correta, isto é, a imagem deve recorrer a um fundo de potência excessiva, de onde ela retira sua força e de onde recorre a possibilidade de a violência se impor.

No fundo das imagens (Nancy, 2003), o inimaginável se irradia, deste fundo de ausência de onde a morte aponta seu nariz e nos faz um sinal. A imagem deve ser colocada fora para fazer-imagem; separada dos olhos ela não cessa este movimento de ir e vir, do mais próximo ao mais distante. Há, verdadeiramente, uma paixão pela imagem, resultante do íntimo e do estranho, do fora e do dentro, paixão que nunca deixa de transtornar aquele que se aventura com seu olhar. A imagem dá a ver, mas também puxa uma força, uma intimidade: "A imagem joga na figura uma intimidade que me chega em plena intimidade" (Nancy, 2003: 16).

A imagem não nos concerne, não a possuímos, pois é ela que, por sua natureza mesma, toca-nos e nos penetra em nosso íntimo. A imagem é esta força íntima, "ela a ativa, a puxa e repuxa, a extrai e a retém, e é com esta força que ela nos toca” (Nancy, 2003: 18). A imagem é desejável como um rosto de onde originalmente ela emerge, levando os traços da história e as marcas das emoções: "ela é uma marca do íntimo e de sua paixão" (Nancy, 2003: 21). A marca é a receptividade de um suporte informe e a atividade de uma forma: sua força está nisso. A ausência que caracteriza a imagem é uma presença intensa: de fato, aquilo que se ausentou para a imagem, o sujeito da imagem, é retirado da superfície, mas não é invisível, sua força é visível. A propósito da semelhança, Nancy escreve: "Vindo na frente ela vai para o interior. Seu interior não é outro que a sua condição de estar à frente: sua condição ontológica é super-fície, ex-exposição, ex-pressão" (Nancy, 2003: 25). A imagem nos seduz e nós a desejamos, queremos tomá-la, captá-la, tocá-la com os olhos, com as mãos e penetrá-la. Esta imagem nos olha, penetra a entrada do íntimo, se "aperta contra si". Gostaríamos de terminar com esta frase de Nancy que lembra a oscilação entre presença e ausência, esta força da imaginação de se representar a presença da ausência: "A imaginação não é faculdade de representar qualquer coisa que está ausente: é a força de tirar da ausência a forma da pre-sença, isto é a força de se representar" (Nancy, 2003: 48; grifos nossos).

Devemos reter, então, que a imagem não é uma simples aparência enganosa, contém também uma força, uma intimidade: ela nos toca, pois nos olha, enfiada, se poderia dizer, sobre o cordão do desejo, ele mesmo preso nos três tempos que são o passado, o presente e o futuro. Seu desvio por uma política do corpo é apenas um abuso e um desprezo: é o que chamamos de tudo-para-a-imagem para o olho gozar (Masson, 2004). 
Para terminar, citemos as proposições de Didier Anzieu (1995) em relação a este texto:

a invenção de Morel é duplamente alegórica. Alegoria literária: um romance não seria também uma máquina de fabricar personagens dotando-os de qualidades sensíveis de tal forma que o leitor os tomaria por seres vivos? Alegoria metapsicológica: a máquina de Morel, com seus três tipos de aparelhos, para a percepção, para gravar e para a projeção, é uma variante metafórica do aparelho psíquico freudiano (Anzieu, 1995: 153).

Reteremos, particularmente, a primeira alegoria, que, de fato, põe em perspectiva a criação como um lugar de imagens e também de sonho, um lugar para as fantasias...

\section{Conclusão. Criação de um neocorpo: o Peso do VirTual}

De fato, é a libra de carne que parece ceder o passo ao virtual, um certo peso da imagem que se captura visualmente e virtualmente. É preciso considerar o duplo sentido do virtual: aquilo que é impotência, suscetível de vir a ser a realidade de nossas percepçôes e aquilo que define um mundo de aparência separado do real (segundo mundo).

Minha questão é saber se estas imagens virtuais se dão a ver como corpo, como chegariam elas a criar um corpo (sem carne)? O espaço virtual é um espaço sem limites, aberto a todas as possibilidades. O corpo é invencível, ele pode tudo e não conhece a interdição, as possibilidades de suas metamorfoses são ilimitadas. Só a potência do desejo dita fatos e gestos. O avatar criado torna-se o modelo daquilo com que é preciso parecer; o modelo é, pois, um corpo virtual. Estamos longe da piada de Picasso de um rico industrial que veio procurar seu retrato e se admira de não se reconhecer: "agora você não tem mais que se parecer!”. Aquele que é vivo não tem mais que parecer com o personagem artificial. Este que se presta a todas as experiências pode cair, voar, desaparecer, reaparecer, ele é a prova de tudo, ele é para sempre. O corpo de carne perde contato com a realidade (a matéria) para tornar-se pura imagem desfeita dos significantes que o compóem. Ele é um corpo novo, sem história, desfeito de sua filiação. Novo personagem que tanto apraz aos assinantes da segunda vida. $\mathrm{O}$ que foi feito das pulsões neste universo? No que elas se transformaram? Estariam elas também atuando de outra forma? 


\section{REFERÊNCIAS BIBLIOGRÁFICAS}

Anzieu, D. (1995). Le Moi-peau. Paris: Dunod.

Ardenne, P. (2001). L'image corps - figures de l'humain dans l'art du XX siècle. Paris: Éditions du Regard.

Baudrillard. J. (1994). Simulacra and simulation. Michigan: University of Michigan Press. Benjamin, W. (1997). L'euvre d'art à l'époque de sa reproductibilité technique. Paris: Carré. Casares, A. B. (1973). Linvention de Morel. Paris: Editions 10/18.

Le Breton, D. (1999). L'adieu au corps. Paris: Ed. Métailé.

Lucrèce, T. (99b.C.-55b.C.). De la nature (De rerum natura). Paris: Éditions de l'imprimerie nationale, 2000.

Masson, C. (2004). Fonction de l'image dans l'appareil psychique: construction d'un appareil optique. Toulouse: Éditions Erès.

Nancy, J.-L. (2003). Au fond des images. Paris: Éditions Galilée.

Offenbach, J. (1881). Les contes d'Hoffmann. Opera.

Sicard, D. (2002). La Médecine sans le corps: une nouvelle réflexion éthique. Paris: Plon

Vernant, J.-P. (2006). Pandora, la première femme. Paris: Bayard.

\section{Notas}

1 Trabalho apresentado no Colóquio Internacional O corpo contemporâneo: psicanálise, cultura e criação, organizado pelas Universidades Santa Úrsula, PUC-Rio e Paris VII, realizado nos dias 29 e 30 de outubro de 2007.

2 Criação mítica de uma simili-mulher.

3 N.T.: No original, se rincer l'oeil: expressão francesa que significa olhar com prazer aquilo que excita os sentidos.

4 N.T.: uma das Nereidas da mitologia grega.

5 N.T.: Sobre a natureza.

6 N.T.: os autores utilizam um jogo de letras e no original escreveram mon(s)tre para fusionar as palavras mostra e monstro.

7 N.T.: monstrance no original.

Recebido em $1^{\circ}$ de agosto de 2007 Aceito para publicação em 30 de novembro de 2007 